\title{
Emerging strategies for supporting student learning
}

\section{A book review of Allan, B. (2016) Emerging strategies for supporting student learning. London: Facet Publishing.}

\section{Helena Beeson}

University of Northampton, UK

Keywords: strategies for supporting student learning; skills; employability.

\section{Overview}

Changing times in terms of fees, student expectations, 'millennials' etc., all demonstrate the need for the shift in thinking that creates the call for this book. The title reflects a very practical, hands-on approach and the book delivers exactly what it says on the cover. This is achieved through case studies and tried and tested methods from a number of international institutions. Specific approaches to teaching and learning are discussed and evaluated from the perspective of librarians and associated tutor roles, although it would be applicable to anyone teaching in higher education (HE) or even further education (FE).

The text reflects the author's background in HE working in libraries and learning and teaching, focusing on the student experience, internationalisation and employability.

This publication is organised in four obvious overarching sections. It starts with the students' needs, including skills and employability, then moves on to the discussion and utilisation of teaching and learning strategies. The third part takes a step back and looks at the preparation and design of some of the more recent teaching methods that many of us will already be aware of. These include the increased use of technology and autonomous learning associated with flipped and blended approaches, along with a discussion around the delivery and evaluation of these methods. Finally, opportunities for professional development are considered, including networking and self-led courses. Throughout the text, lots of case studies illustrate some of the practices used as examples and to 
demonstrate how differently organisations and individuals approach similar issues successfully.

\section{Structure and content}

At the beginning of the book, the question is raised about whether we as professionals consider the technological needs and expertise of our learners, establishing a loose theme for the book around the diverse nature of the student body. The importance of preparing for and responding to ongoing change faced by HE is stressed and complemented by a renewed call for collaboration between library staff, course tutors and other support teams. A challenge to student stereotypes is offered in an overview of different groups in chapter two, along with the various approaches and methods we have for interacting with each of them. This reflects the recent valuable shift in working with our learners as partners in their own learning, although in my own experience there are still a number of undergraduates who want to be told what to do with specific instructions on tasks and handholding throughout assignments. As the Jisc report for Technology for employability states (Chatterton and Rebbeck, 2015), graduates are not 'work-ready' and need to be empowered as self-aware independent learners. Student attitudes are not discussed in the text or covered in wider research particularly, but there is a great deal focused on engagement strategies and technology throughout the literature.

The author explores a range of literacies including digital literacy and media literacy. Allan discusses how these can contribute to redesigning teaching approaches, including quizzes, organised events, and establishing one's own online identity. Notably, this section promotes the shift of information literacy from a prescriptive, linear approach, to reflect the more chaotic reality of the trial and error nature of research. Several frameworks are introduced which address different points of focus, for example, digital literacy competencies (a model of applied information literacy which promotes collaboration and digital badges for accomplishment).

Employability is a general theme which runs throughout the text, but it is discussed specifically in terms of our professional role in contributing to graduate attributes. Peer learning and working with students to cultivate their own university experiences are suggested as useful strategies. This is an area librarians have been working towards for many years from a more individual student perspective, but in order to promote all 
employability opportunities, Allan emphasises the importance of aligning with all areas of the university, including taking a proactive role in shaping strategic developments.

Common teaching and learning approaches are explored and evaluated, including the use of reflection and group working. Practical applications of these are offered in the guise of almost everything from lectures to gamification to podcasts. These are considered as largely student-led with some useful tips and appropriate plans for delivery. The only notable omission here is the use of Lego in teaching which has been a source of debate recently for learning developers as to whether it represents the infantilisation of teaching or an exciting opportunity for enabling learning (James, 2015). The arguments for student engagement and social learning are also presented which are at the core of our experiences as tutors and librarians. In fact, this area could be developed into another book in its own right given the changing nature of students and expectations over the last few years.

The book then takes a step upwards in the hierarchy of delivering teaching and discusses how these strategies can be incorporated in the programme design level. It stresses the importance of constructive alignment whereby activities need to be planned to reflect designated learning outcomes. To reinforce this, the basic design principles of courses are also taken into account. The planning of individual activities is woven in well through the use of Bloom's taxonomy, existing pro-formas and the identification of a number of resources which can be reused and repurposed. Flipped and blended learning approaches are demonstrated positively from a librarian's perspective. Most of this section discusses asynchronous tools and techniques where students do not have to engage with study at the same time, and avoids the technical issues often connected with synchronous learning which can affect distance learners in various time zones and those with poor internet connectivity.

The practicalities and detail associated with teaching are covered in depth in order for the reader to be as prepared as possible for any challenges and opportunities they may face as an effective teacher. This includes both face-to-face and online provision, timing, and elements of emotional intelligence. It appears that this section is aimed primarily at those new to teaching, although this is not stated explicitly (bar a short section on embedded librarians). Some of the good practice guidelines would have been useful for me as an Assistant Librarian back when we were concerned about the millennium bug, while others 
demonstrate how far such beneficial technology has come in recent years. It serves as a useful refresher today and the up-to-date case studies demonstrate the specific issues associated with the discussed approaches.

The question of quality provides a valuable discussion point with the observation that many of the teachers working within library and information services may not be subject to the same quality processes as the rest of their institutions. It is therefore recommended that librarians and their teaching colleagues should identify their institution's stance and relevant policies in order to inform their approach. The UK Quality Code for Higher Education is explained in detail which will undoubtedly be useful to anyone who has not come across it in this field. The evaluation of the quality of learning and teaching activities from a library perspective is explained in depth with a range of both qualitative and quantitative measures investigated to determine impact. These include statistics and analytics, interviews, key performance indicators and focus groups. However, there is no link back to the UK Quality code provided here which would have been useful.

The final part of this hands-on and accessible text is concerned with professional development and appears to be aimed at newly qualified librarians and information workers. Options for networking and the benefits of a number of international library and information professional associations are discussed. There is no mention of any limitations, however, such as cost. Workshops, self-led courses and online networks are offered and explored as strategies for professional growth which includes a number of well-known websites.

Overall, this book represents a good snapshot of where our professions are at currently, along with some of the challenges we are facing in our ever-evolving roles. More could be included in places, but part of the appeal of the text is that it is designed to offer guidance succinctly and perhaps quickly at a time of need. To this end the language is very clear and accessible. Useful practical approaches for teaching are offered throughout and each chapter comes armed with an impressive list of case studies and references so you know you are in safe, informed hands with this book. 


\section{References}

Chatterton, P. and Rebbeck, G. (2015) Report: technology for employability. Study into the role of technology in developing student employability, Jisc. Available at: http://repository.jisc.ac.uk/6249/3/Technology for employability - full report.PDF (Accessed: 23 May 2016).

James, A. (2015) Innovating in the creative arts with Lego. Available at: https://www.heacademy.ac.uk/innovating-creative-arts-lego (Accessed: 1 June 2016).

\section{Author details}

Helena Beeson is an Academic Practice Tutor at the University of Northampton and practised as an Academic Librarian for 10 years. Research interests include reflection and collaboration. She has a reputation for grammatical pedancy. 